\section{sciendo}

DOI: $10.2478 /$ ncr-2018-0008

(c) Article authors. This is an open access article distributed under the Creative Commons Attribution-NonCommercial-NoDerivs licens. (http://creaticecommons.org/licenses/by.nc-nd/3.0/).

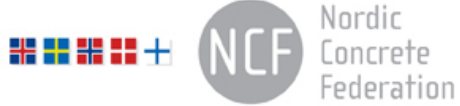

ISSN online 2545-2819

ISSN print $\quad 0800-6377$

Received: March 22, 2018

Revision received: May 29, 2018

Accepted: May 29, 2018

\title{
Continuous Preventive Bridge Maintenance of Swedish Municipalities - A Survey on Common Practice
}

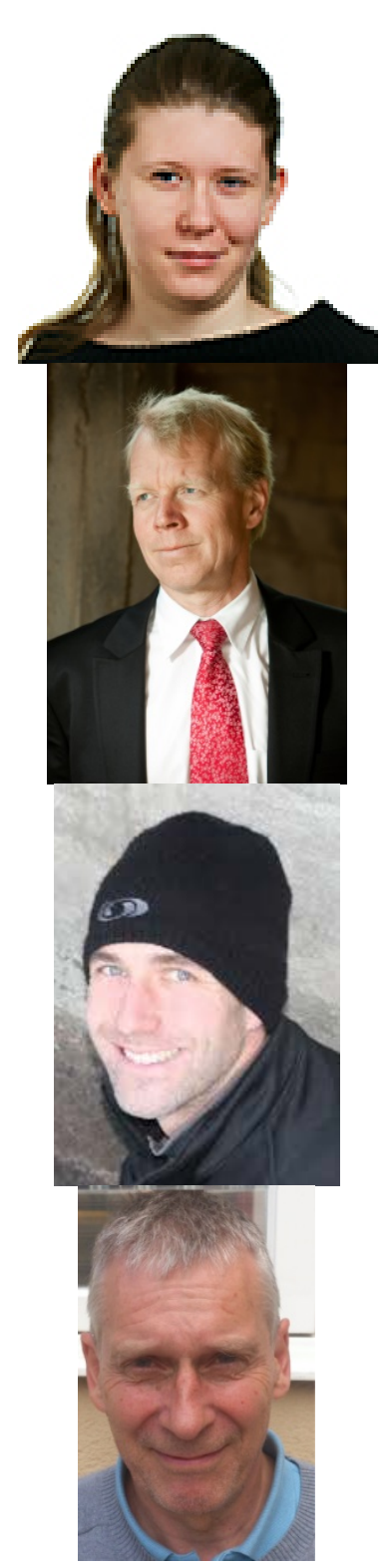

\author{
Louise Andersson, \\ MSc, PhD student \\ RISE Swedish Cement and Concrete Research Institute \\ Drottning Kristinas väg 26 \\ SE- 100 44, Stockholm \\ E-mail: louise.andersson@ri.se \\ Johan Silfwerbrand, \\ PhD, Professor \\ KTH Royal Institute of Technology \\ Dept. of Civil \& Architectural Engineering \\ Brinellvägen 23 \\ SE-100 44 Stockholm \\ E-mail: jsilfwer@kth.se
}

Anders Selander,

MSc, PhD

CEMENTA

Cementa AB, Heidelberg Cement Group

Marieviksgatan 25

SE-100 74 Stockholm

E-mail: anders.selander@cementa.se

Jan Trägårdh,

MSc, Lic. Of Phil

RISE CBI Swedish Cement and Concrete Research Institute

Drottning Kristinas väg 26

SE- 100 44, Stockholm

E-mail: jan.tragardh@ri.se 


\begin{abstract}
As part of a report [1] on continuous preventive bridge maintenance, a survey was conducted with Swedish municipalities. The survey's focus was on bridges and preventive maintenance, as well as the demands and performance control stated by the municipalities. The preventive maintenance the survey focused on was the annual maintenance concerning washing, cleaning of drainage system and removal of vegetation. The survey showed both similarities and differences within the municipalities but also in comparison with Swedish Transport Agency (STA).
\end{abstract}

Key words: bridge maintenance, preventive maintenance, survey.

\title{
1. INTRODUCTION
}

In Sweden, the primary owner of the country's over 30000 bridges is the state, through the Swedish Transport Administration (STA) [2]. This of course means that the vast majority of knowledge and experience exists within this organization. But a few thousand of bridges belong to Swedish municipalities. As part of a pre-study [1] on the preventive bridge maintenance in Sweden, the STA's experience and requirements [3]-[10] were examined. The question about possible similarities and differences between municipalities arose. Therefore a survey was conducted with the goal of examining the municipalities' bridge maintenance. The results from the survey and pre-study are the base used in further research that will examine the effect of washing on concrete bridge elements.

\section{BACKGROUND}

The majority of Swedish bridges were constructed during the three decades between 1950 and 1980. They have now reached an age of 40-70 years and many of these bridges are in need of repair if they have not already been repaired. The knowledge on durability was less during this period which means that the deterioration processes go faster than what will be anticipated for modern bridges which are constructed for a service life of 120 years. However, both old and new bridges need some kind of maintenance in order to reach the intended service life and fulfil the performance criteria. From a sustainability point of view, every year of prolonged use leads to less use of new virgin construction materials and, thus, less environmental footprint.

The maintenance is traditionally divided into preventive and corrective maintenance, but the wording and definitions may vary. In Sweden, STA has made the definitions and developed the requirements as stated above. The preventive bridge maintenance consists of simple measures, e.g., water washing, cleaning, vegetation removal, crack repair, material refill, and stretching of bridge railings. The Swedish preventive bridge maintenance has been analysed and criticized [11-12] and research needs has been identified. A hypothesis is that improved preventive bridge 
maintenance will be a cost-effective measure to prolong the bridge's service life and improve its performance. Current research project is a result of these efforts.

As a minor part of a pre-study on the continuous preventive maintenance of Swedish bridges [1], a survey was sent out to municipalities. 17 replies were sent back of over a 100 contacted municipalities. In total there are 290 municipalities in Sweden. Over 210 of these municipalities use the database designed for bridge and tunnel management (BaTMan), created and managed by the STA. In total there are over 30000 bridges in Sweden and the vast majority of them belongs to the STA [2]. Due to this, the STA and its predecessors are the leading source for requirements of bridge maintenance in Sweden. BaTMan contains a lot of structural information on bridges, results from inspections and measures but nothing concerning the washing or cleaning is registered in the database. The procedures and controls contracts used by the STA are based on information from BaTMan, such as information about length of edge beams, length of bridge joints and number of drainages. Several municipalities use and adapt the requirements and procedures used by the STA [5], [8] \& [10]. But due to the information gathered in the survey, there are some factors the municipalities do differently and have a different view on than the STA. Noteworthy is that for a lot of municipalities, there has been unwanted neglect of bridge maintenance or prioritizing due to lack of funds. For several municipalities in the survey, and even information from non-participants, there has been an increase in funds and prioritizing of infrastructure in recent years. This has resulted in an increased standard of bridges enabling "catch up" maintenance and repairs. Most municipalities in the survey are still in the phase of catching up and some are just starting. From a maintenance point of view it is positive to increase funds for maintenance in order to avoid or delay major repairs.

As mentioned, this survey was considered to constitute a minor part of a pre-study. However, there are a lot of interesting answers from the responders that presented a good indication of the situation. The survey's goal was to examine similarities and differences between the STA and municipalities and between the municipalities. The lack of variation in geographical location resulted in that its influence could not be examined.

\section{3.} METHOD

A survey was sent out to representatives or responsible persons of bridge maintenance in the municipalities. Depending on the size of the municipalities and the amount of bridges the maintenance responsibility could include a small side task for one person to divided responsibility between many people. All surveys that were filled in, except one, generally answered all the questions completely.

The responders either filled out the questions on their own or over the phone with the first author. A translated version of these questions can be seen in the appendix as the original is in Swedish. 


\subsection{The responders}

The responses are from representatives of 17 municipalities in Sweden. All except one are located in the middle and south of Sweden. Nine municipalities are located along the coast sides (five on the west coast and four on the east coast). An additional three are located near the capital, Stockholm. The last five municipals are all located near one of the three biggest lakes in Sweden.

Despite few responses, observed differences and similarities in answers have given a good initial indication of the situation between municipalities themselves and in comparison with the STA. In the questionnaire the municipalities could choose between allowing the name of person and municipalities to be published in the report and total anonymity with steps in-between. As some choose total anonymity, no municipalities will be referenced by name in this article for consistency. The 17 participating municipalities generally gave thorough answers and additional interesting information beyond what the questions required. Some of these answers will be presented as examples by those that gave their permission.

The contacted municipalities were chosen from a process where municipalities with a population under 15000 and those that had fewer than five bridges in BaTMan were eliminated. Of the over 100 municipalities contacted, more than half didn't respond at all. Several responded that they were quitting or just started and therefore could not answer as they were themselves trying to get to grips with the matter. A few also referred to their contractors, which was not the group of interest for this survey, as the goal was to examine the municipalities, but could be of further interest when comparing and examining contractors.

\subsection{The survey}

The survey consisted of 31 questions where 16 were multiple choice questions and the rest generally required short answers. For each question there was an option for comment, which mostly was used to explain, give examples or provide additional information that would be of interest. A translated version can be seen in full in the appendix.

\section{RESULT}

Initially there was a wish for diversity and many replies, but the end result was few but satisfactory. The initial goal of the survey was to detect similarities and differences between municipalities and the STA. Some of the municipalities were under change in several aspects, from economically, contracts, investments, personnel, etc. In that case the municipality reported both the current situation and the future one. For future changes, it could mean from weeks to years depending on nature, extension, and degree of the change. 


\subsection{General facts}

While there wasn't a satisfactory diversity in geographical location, there was a good diversity in number of bridges in each municipality, see Figure 1 . The number of bridges owned by a municipality ranged from 22 to over 200. The municipality with the highest number of structures had over 800 bridges registered in the database BaTMan. The municipality commented however that the number was a bit misleading. This is because other types of structures are registered as bridges in the database. For example traffic decks were registered as bridges, and continuous bridges could be registered as one single bridge or as several bridges. The exact number of bridges was thereby uncertain.

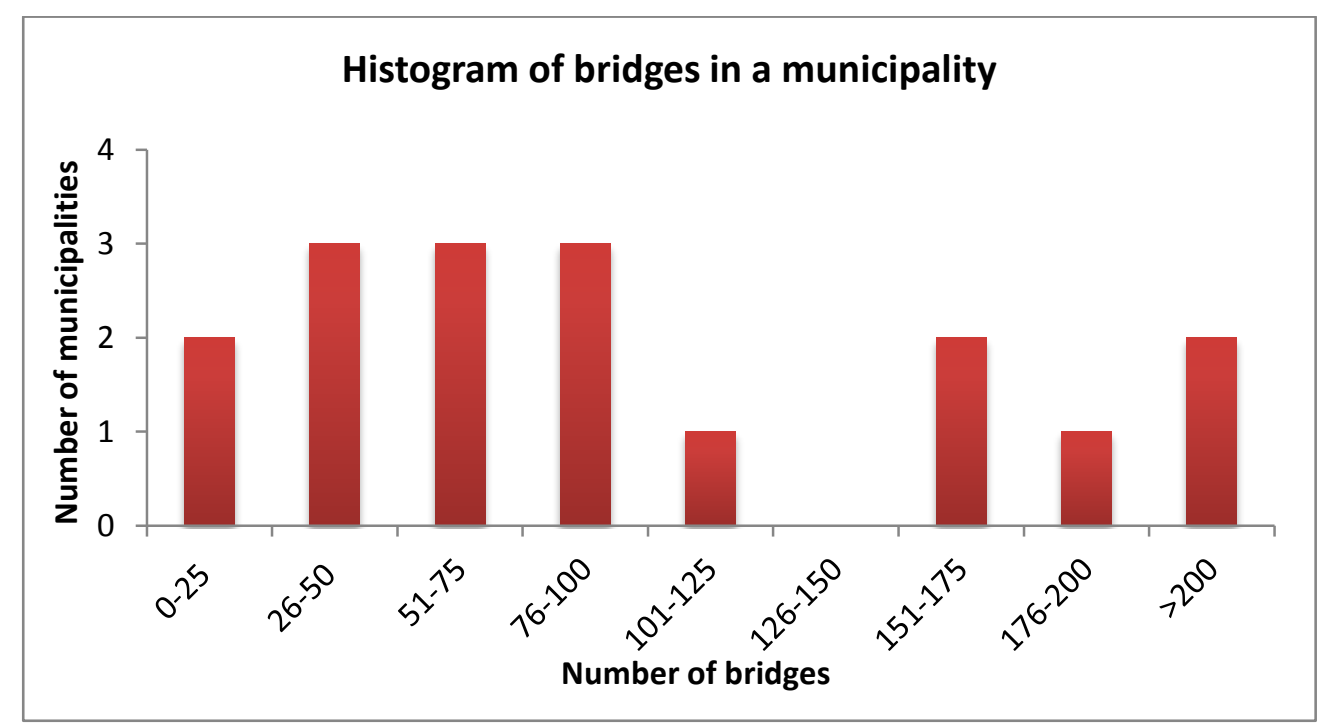

Figure 1 - Histogram over the number of bridges of the participating municipalities.

For the majority of the municipalities the main construction material of their bridges was reinforced concrete or a combination of steel and concrete. A few municipalities had smaller timber bridges, usually only for pedestrians. In most municipalities there was around the same number of pedestrian bridges as road bridges. Otherwise road bridges were more common. Only for one municipality were pedestrian bridges more common than road bridges. Five of the responders had movable bridges, in range from 1 to18.

The municipalities' budgets for bridge maintenance varied between them, with no clear relation, except maybe incitements from the politicians. Some had very large budgets and others smaller ones. No direct correlation between the budget and the number of bridges or population could be seen. Simple tests with the least square method $\left(\mathrm{R}^{2}\right)$ showed around almost no correlation between municipalities' budgets with the number of bridges, population or area. The $\mathrm{R}^{2}$ values for a trend lines was between 0.07 and 0.12 , as one example shows in Figure 2. Even if the municipality with the most eccentric result in Figure 2 is removed the $\mathrm{R}^{2}$ value only increases a bit on the second decimal. This indicates that there is no distinct correlation with the maintenance budget and these individual factors. The only factors that had high $\mathrm{R}^{2}(0.73)$ value were unsurprisingly between the population and the number of bridges. Some municipalities 
had large budgets in order to catch up on required maintenance and repairs. Some were doing repairs after several decades of only acute maintenance and repairs. These investments were both short and long term. Some municipalities were going to start and some were in the middle or end of their catch up repairs. Generally, there seems to be an effect of political decisions to invest in infrastructure. To the frustration of the people working with bridge maintenance there is always a shortage of means in comparison to required maintenance. Thereby there is always a choice on what needs to be prioritized.

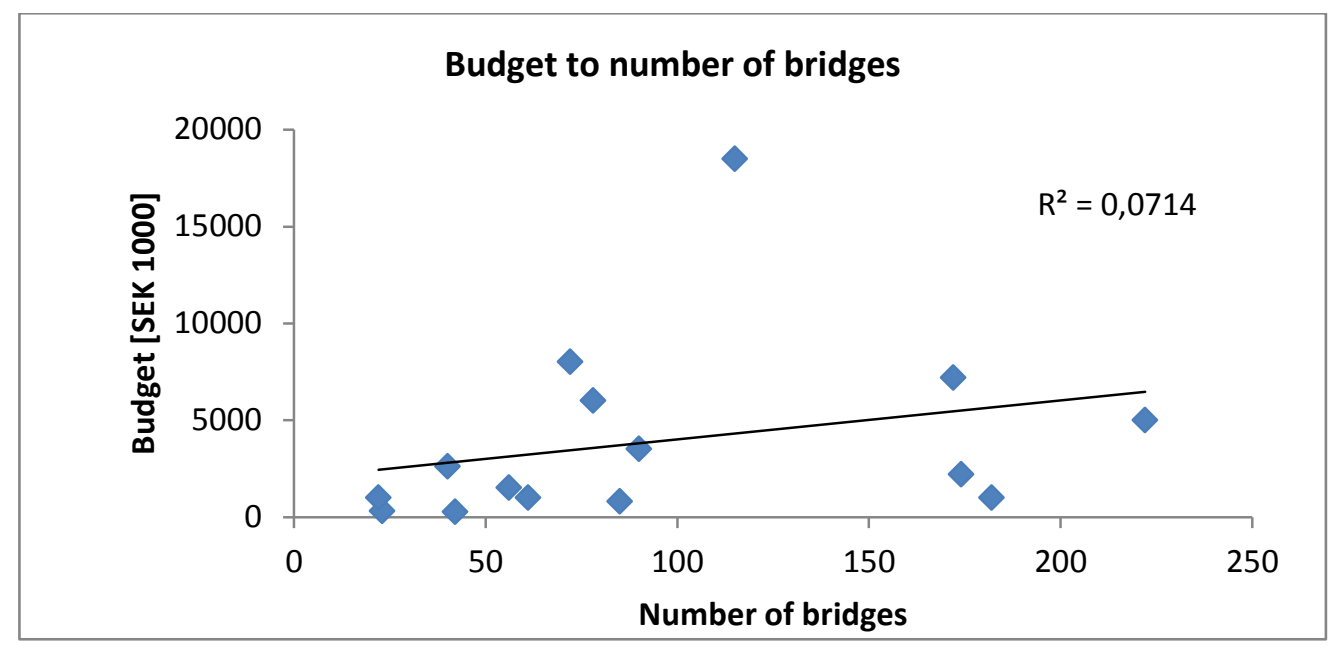

Figure 2 - Diagram with the number of bridges in a municipality plotted against the budget.

The STA uses something they call "integrated bridge maintenance" [13]. It is simplified a way to improve the efficiency of bridge maintenance. By having contractors working in determined geographical areas as to conduct maintenance for bridges in geographical closeness to oneanother to increase time efficiency and reduce costs. The integrated bridge maintenance contract also includes minor repairs on selected bridges during the contract period. The STA's experience with the integrated bridge maintenance have had positive with better efficiency and reduction in costs.

For the participating municipalities, four responded that they use integrated bridge maintenance. Another two responded that they were planning to implement it in the future. Some of the municipalities that didn't use integrated maintenance motivated this by the fact that their geographical area was too small.

Two thirds of the municipalities use annual scheduling for their continuous preventive bridge maintenance. Most scheduled activities are inspections, washing and cleaning of drainage in correlation with when the gritting sand from the winter season is collected.

The municipalities were asked the question of who's responsible for the maintenance of a bridge when the ownership is shared. Shared bridges are not common and usually exist when the bridge is geographically located at the border between municipalities. Another possibility is that one part of the bridge belongs to the STA and another part belongs to a municipality, this is usually when roads belonging to each part meet or are connected to each other by ramps for example. 
The responses can be seen in Figure 3, where the left circle shows how many of the municipalities share bridges (65\%) and those that don't share or didn't respond to the question (35 \%). In that case it has been assumed that the municipality don't share any, as it was an extended question. The right circle shows the answers for those municipalities that answered "yes" to shared bridges. The majority answered how they share responsibility and cooperated. The municipalities often specified or gave examples of what each part did. Usually it was different types of maintenance. For example, one municipality answered that they were responsible for the electronics on the bridge and removal of graffiti. Otherwise the answers were evenly split between doing all of it themselves or it was depending on the bridge concerning responsibility.

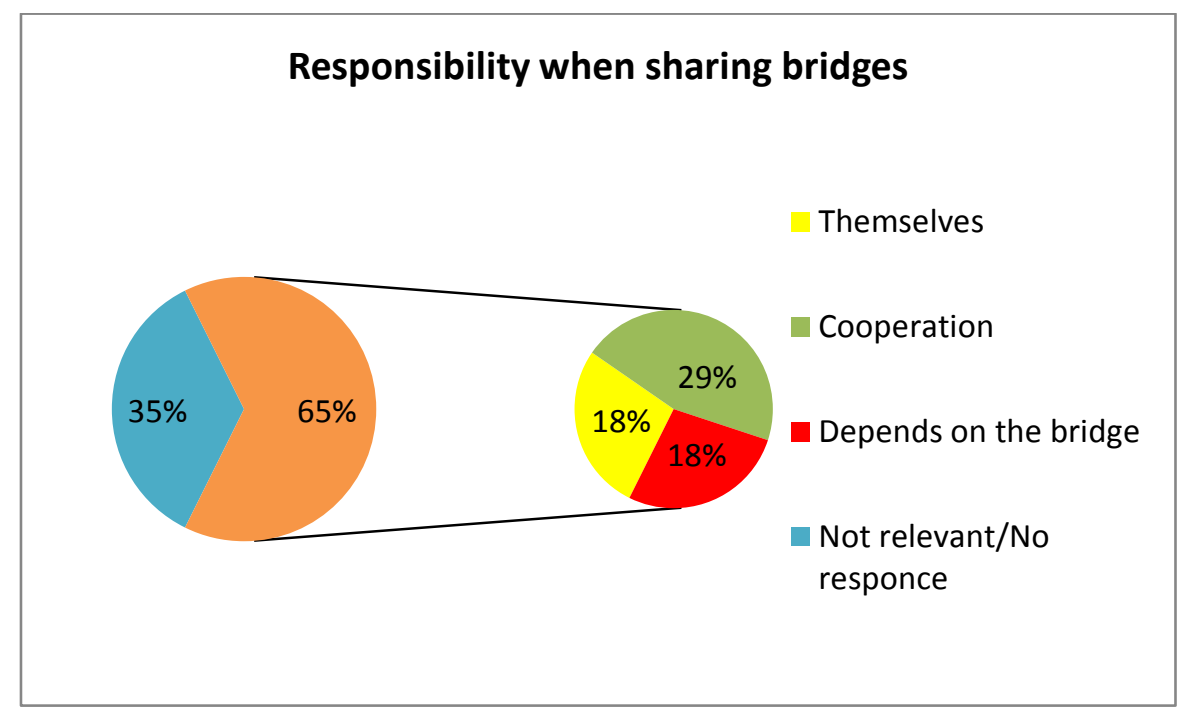

Figure 3 - Diagrams over who is responsible for maintenance of a bridge when the ownership is divided. The left circle shows the percentage of those that share and don't share or didn't answer. The right diagram shows the responsible part when sharing bridges.

\subsection{Contracts for bridge maintenance}

The STA has been using contractors for the practical aspects of the maintenance for the last decades. The assumption that municipalities also did was examined.

All of the municipalities have contracts with consultant firms for the inspection of the bridges, similar to the STA. Two municipalities did this partly, where some small and simple bridges were inspected by their own personnel. One municipality stated that they inspected the small timber bridges in the forest on their own. These bridges were not in BaTMan and the municipality specified that only those registered in BaTMan were inspected by consultants.

The washing of bridges was generally done by contractors (10 municipalities). The rest either had contractors doing some of it or the municipalities did everything themselves. For removal of vegetation the municipalities were almost evenly split between using only contractors, partly contractors and or by the municipalities themselves. One municipality couldn't answer who was 
responsible for the washing and removal of vegetation as this was the responsibility of another division and considered a part of the road maintenance.

Cleaning of drainage systems was either fully or partly done by contractors. Only two municipalities didn't use any contractors for cleaning the drainage system. For both small repair and controls the operation was usually done by contractors. A few municipalities didn't use contractors at all.

Five municipalities used contractors for everything, two municipalities partly used contractors for everything, excluding inspection. One municipality didn't use contractors at all except for inspections. The rest had varied or mixed usage of contractors.

\section{3}

\section{Inspection}

In Sweden there are different types of bridge inspections that have different levels of thoroughness and have different recommended frequencies[14].There are three major inspection types with corresponding frequency of 1,3 and 6 years. The lower the frequency of the inspection, the more detailed and thorough inspection. The municipalities used one or more of these types. Some municipalities also made one or several of their own minor inspections. It is common that maintenance contractors perform continuous supervision and should report if they find any damage or something not functioning. There were some exceptions to the normal frequency of inspections. One municipality reported that they inspected their movable bridges every fortnight during sailing season.

The inspectors from the consultancy firms get a certain period or dates where they can do their inspections. Usually this is done during the warmer season but can happen at any time during the year. There was a great range between the consultancy firms used by the municipalities, where almost every municipality used a different firm.

\subsection{Maintenance}

Due to the winter conditions in Sweden, the use of de-icing salts is common practice. The use of it in the municipalities is therefore an important aspect to consider, especially because de-icing salt contributes to corrosion of steel and of the rebars in concrete. A special focus in Sweden is on the edge beams, which constitute a continuous problem. The participants were asked when the salting occurred and how many of their bridges that were directly exposed to de-icing salts. Almost all of the participants used de-icing salts on their bridges to some degree, see Figure 4. Some municipalities only use de-icing salts on their road bridges or, as one municipality commented, only on the roads used by public transport. The geographical location of the municipalities didn't indicate any influence on the amount of bridges exposed to de-icing salts. 
For municipals located next to each other or very close, one municipality usually had a high number and the neighbour a low one.

The period for using de-icing salts was quite consistent for the 15 municipalities that used deicing salts. Unsurprisingly, the main period is during the winter months but as all the municipalities commented on, it depends on the weather conditions and prognosis. All had December to February with most also including March (87\%) and November (73\%). A few also said April and/or October. This could of course be because the question was interpreted differently with some only stating all of the possible months and others only stating the most common ones.

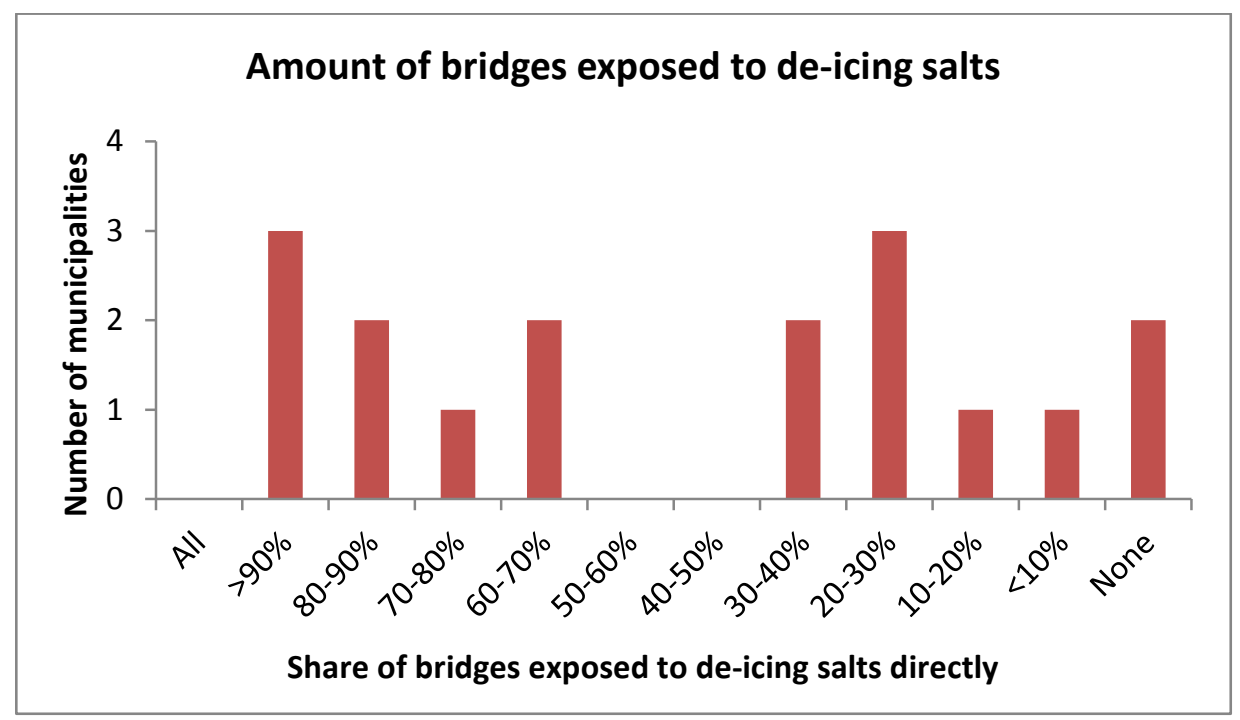

Figure 4 - Histogram showing what percentage of a bridges within a municipality are directly exposed to de-icing salts

Washing of bridges occur when the winter season is over and after the collection of grit sand used for ice prevention during the winter. The main period of washing is late spring and/or early summer, but could also be done later, see Figure 5. The municipalities usually have a period or a date of when the washing of bridges should be done. Some also have a specified starting date when work can start, which is usually in April or May. The municipals that answered August to November also had washing done in May and/or July, indicating two washing periods. The STA states in their contracts for integrated bridge maintenance [15] that the period for washing is generally from the middle of May to the middle of July. The geographical location indicated no influence on the period of washing. 


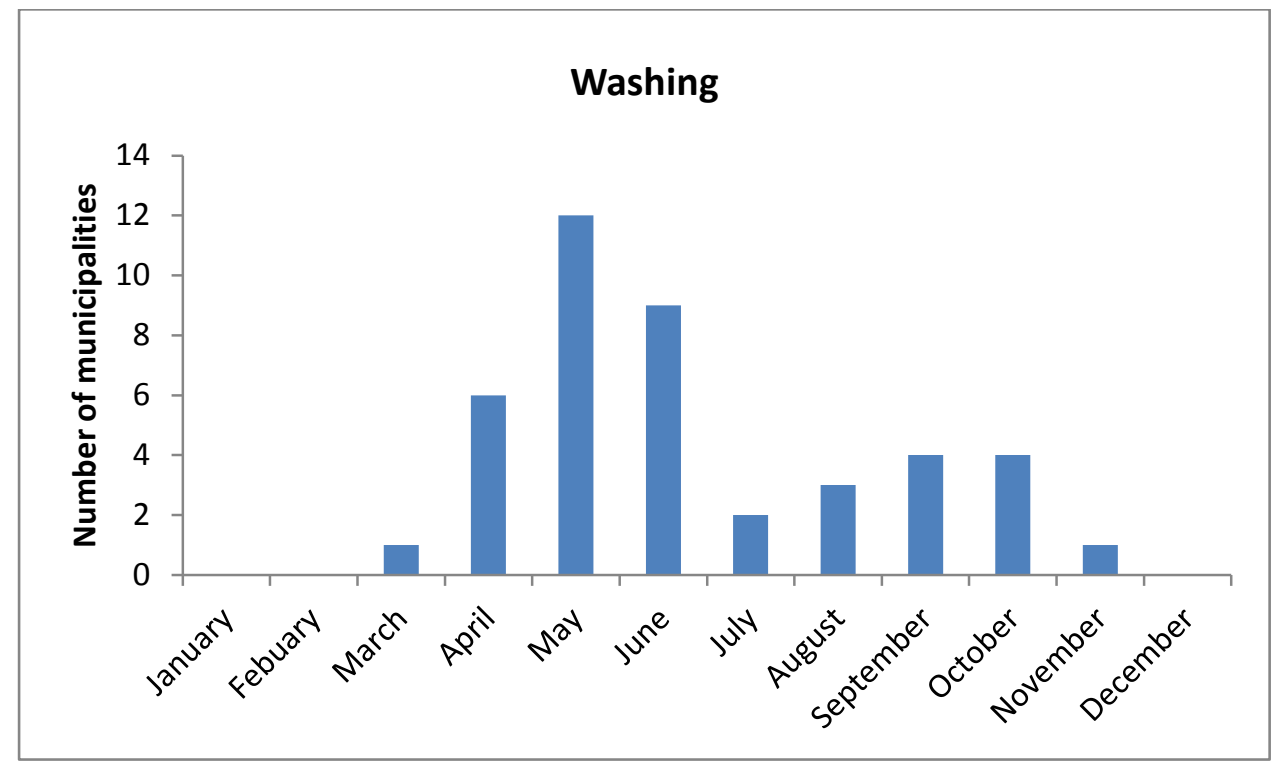

Figure 5 - The period of a bridge washing in the municipalities.

\section{5}

\section{Demands}

The majority of the municipalities reported that they used the STA's current demands (TDOK 2013:0415) [4] and advice (TDOK 2013:0416) [7] for bridge maintenance. Of these 17 municipalities only two had additional demands than those based on the STA's. Another two municipalities had occasionally more demands. But the majority didn't have more requirements than those the STA has for bridge maintenance. Some comments from the municipalities indicated, however, the usage of older versions' demands. Certain comments were made on demands on washing that were the same as in the STA's older versions [9], [10] but not the newer one. This can be the result of preferences or lack of knowledge of updates. When asked for their demands on washing, the municipalities either referred to STA's or answered edge beam, bridge bearing \& pillars, railings, drainage systems etc. The majority of the municipalities felt that their demands were being fulfilled. Only a quarter of the municipalities felt that the demands had been fulfilled partly while the rest felt that it had been fulfilled completely. One municipality commented that it had shown flaws during checks and another commented that their subsidiary didn't have the right equipment, making it hard to reach and perform the maintenance correctly.

\section{6}

\section{Problems and actions}

The most common problems for bridge maintenance in municipalities were quite different depending on the municipality and interpretation of the question. The answers touched upon railings, joints, edge beams, accumulations, different surface damages, economy etc. and no municipality answered the same. Many municipalities responded with a few different answers. 
This also reflects the different and many issues that exist with the bridges. Some problems could be solved with washing and cleaning while other requires minor or major repairs.

There is a consensus amongst the participants that the actions taken on their bridges have had a positive effect on the standard of the bridges.

\subsection{Control}

The people that performed the controls of maintenance were generally different consultants, contractors or someone from the municipalities' own staff. The way to make sure the maintenance has been performed correctly and the demands have been met is mainly by selfmonitoring and/or sampling controls from the municipalities. In the case of shortcomings it is usually solved by the contractors having to redo it on their own expense or by form of a penalty. During the year of the survey, the controls had been positive for most of the municipalities. A few had larger faults that needed to be corrected. One municipality that for a long time had to neglect maintenance has in recent years received a larger budget to deal with their problems. The municipalities have noticed an improvement in recent years, which shows that investments in infrastructure have positive effects.

Noteworthy is how much maintenance and repairs that can be done depends heavily on the municipality's budget where they have to prioritize, which for a long time meant doing few things on the bridges that are in the greatest need and neglect other bridges which resulted in more problems on the other bridges and higher repair costs.

\subsection{Definition of preventive bridge maintenance}

The participants were finally asked how they would define preventive bridge maintenance. The answers could be divided into four categories where the municipalities only gave one answer or a combination of two or several ones. The categories are:

- Cleaning- washing, removal etc. (60\%).

- Impregnation and small repairs (60\%).

- Continuous supervisions and/or actions done on time (40\%).

- Improve or preserve the bridge standard or value (33\%).

According the standard for maintenance terminology EN 13306:20 [16] the definition for preventive maintenance is:

"maintenance carried out at predetermined intervals or according to prescribed criteria and intended to reduce the probability of failure or the degradation of the functioning of an item " 
This definition can be in agreement to the responses from the participants, with their answers fitting within the definition.

\section{CONCLUDING REMARKS}

The survey showed both differences and similarities between municipalities. The actual maintenance, demands and controls of the bridges are generally the same, but when and by whom it is done differentiate greatly, which could have an effect on the efficiency of the washing. This is probably connected to the way that the municipalities use and adopt the demands and recommendations previously used by the STA as well as their own previous experiences. The survey also showed that each municipality often had a separate issue or solution that was a result of their bridge stock or the budget. An unspoken consensus among the answers seemed to be that having to prioritize and neglect certain maintenance only increases the problems later on. There is always more to be done than can be met with available means.

The survey shows that the washing of the bridges often starts late. This means that the chlorides from the de-icing have all the time during winter and most of the spring to migrate into the concrete before the washing. This may affect both frost attack and corrosion of rebars. Research on the effect by washing is therefore of interest.

\section{REFERENCES}

1. Andersson L: "Det kontinuerliga förebyggande underhållet av broar - en förstudie” ('The continuous preventive maintenanc of bridges - a pilot study"), Report, RISE CBI Betonginstitutet, Stockholm, Sweden, 2018. (In Swedish).

2. Swedish Transport Agency: "BaTMan Bridge and Tunnel Management, Swedish Transport Agency, 2018. [Online]. Available: https://batman.trafikverket.se/externportal. [Visited October 2017]. (Database in Swedish).

3. Swedish Transport Agency: "TDOK 2013:0415, Version 1, Demands Bridge maintenance,” Swedish Transport Agency, Borlänge, Sweden, 2013. (In Swedish).

4. Swedish Transport Agency: "TDOK 2013:0415, Version 2, Demands Bridge maintenance,” Swedish Transport Agency, Borlänge, Sweden, 2015. (In Swedish).

5. Swedish Transport Agency: "TDOK 2013:0415, Version 3, Demands Bridge maintenance,” Swedish Transport Agency, Borlänge, Sweden, 2017. (In Swedish).

6. Swedish Transport Agency: "TDOK 2013:0416, Version 1, Bridge maintenance Advise," Swedish Transport Agency, Borlänge, Sweden, 2013. (In Swedish).

7. Swedish Transport Agency: "TDOK 2013:0416, Version 2, Bridge maintenance Advise," Swedish Transport Agency, Borlänge, Sweden, 2015. (In Swedish).

8. Swedish Transport Agency: "TDOK 2013:0416, Version 3, Bridge maintenance Advise," Swedish Transport Agency, Borlänge, Sweden, 2017. (In Swedish). 
9. Swedish National Road Administration: "Bridge maintenance 2006, Publication 2006:146” Swedish National Road Administration , Borlänge, Sweden, 2006. (In Swedish).

10. Swedish National Road Administration: "VVK Bridge maintenance 2010-03," Swedish National Road Administration , Borlänge, Sweden, 2010. (In Swedish).

11. Silfwerbrand J: "Technical Demands for Preventive Bridge Maintenance- A Critival review,” Procedings, fib Symposium "Concrete Structures- Sitimulators od Development" pp.871-880, Dubrovnic, Croatia, 2007.

12. Silfwerbrand J: “Improving Preventive Maintenance,” ACI Special Publication No. SP277CD ("Recent Advances in MAintenance and Repair of Concrete Bridges"), pp. 67-78, American Concrete Institute, Farmington Hills, Michigan, USA, 2011.

13. Swedish Transport Agency: “Bridge maintenance," 14 December 2017. [Online]. Available: https://www.trafikverket.se/for-dig-i-branschen/vag/underhall-vag/Bro-ochtunnel/brounderhall/. [Used 10 March 2018]. (In Swedish).

14. Swedish National Road Administration: "BRO Manual for bridge inspection," Swedish National Road Administration, division of road \& trafic, Borlänge, Sweden, 1993. (In Swedish).

15. Swedish Transport Agency: "Contract document- Integrated bridge maintenancce- Time controlled maintenance-Jönköping- Technical description,” Swedish Transport Agency, Sweden, 2014. (In Swedish ).

16. SIS Swedish Standards Institute, "SS-EN 13306:2010 Maintenance- Terminology,” SIS Swedish Standards Institute, Stockholm, Sweden, 2010. (In Swedish).

\section{APPENDIX SURVEY QUESTIONS}

(This is an English translation of the Swedish original)

\section{Preventive bridge maintenance - A survey for municipalities}

Generally about bridges

1. How many bridges are you responsible for?

(In this case bridges is defined as having a theoretical span of more than 2.0 meters)

\begin{tabular}{|l|l|}
\hline Total & \\
\hline $\begin{array}{l}\text { Road } \\
\text { bridges* }\end{array}$ & \\
\hline $\begin{array}{l}\text { Pedestrian } \\
\text { bridges* }\end{array}$ & \\
\hline Other* & \\
\hline Movable & \\
\hline Fixed & \\
\hline
\end{tabular}

*Not necessary but would be helpful Comment:
2. How many bridges are there with the following construction material?

\begin{tabular}{|l|l|}
\hline Concrete & \\
\hline Steel & \\
\hline Concrete & \\
\& steel & \\
\hline Wood & \\
\hline Stone & \\
\hline Other & \\
\hline
\end{tabular}

Comment:

3. How much money in the municipality is spent on maintenance each year?

Answer: 
4. How much is in a preventive purpose? (for example washing, removal of vegetation and minor repairs)

Answer:

5. Do you use integrated bridge maintenance?

(Bridge maintenance contracts on STA's bridges are divided based on geographical location, called integrated bridge maintenance package. These packages include both time-controlled (preventive) and state-controlled (remedial) bridge maintenance. In this case, bridges located within a geographic area are maintained within a period of time. You "perform maintenance on several bridges while in the area”)

$$
\square \text { No }
$$$$
\text { Yes }
$$

Comment:

6. For which services do you use contractors?

$\begin{array}{lccc} & \text { Completely } & \text { Partly } & \text { Not } \\ \text { Inspections } & \square & \square & \square \\ \text { Washing } & \square & \square & \square \\ \text { of bridges } & & \square & \square \\ \begin{array}{l}\text { Removal } \\ \text { of }\end{array} & \square & \square & \\ \begin{array}{l}\text { vegetation } \\ \text { Cleaning } \\ \text { of drainage }\end{array} & \square & \square & \square \\ \begin{array}{l}\text { Small } \\ \text { repairs }\end{array} & \square & \square & \square \\ \begin{array}{l}\text { Control/ } \\ \text { Checks }\end{array} & \square & \square & \square\end{array}$

\section{Comment:}

7. Is there a time schedule for the year?

$$
\begin{array}{ll}
\square \quad \text { Yes } \\
\square \quad \text { No }
\end{array}
$$

Comment:
8. If you share responsibility of bridges with the STA and/or other municipals. Who is responsible for maintenance?

\begin{tabular}{|c|l|}
\hline$\square$ & Yourself \\
\hline$\square$ & STA/Other municipals \\
\hline$\square$ & Cooperation \\
\hline$\square$ & Depends on the bridge \\
\hline
\end{tabular}

Comment:

Inspection

9. Do you do the inspection yourself or does a consultant?

$\square \quad$ Ourselves

$\square$ Consultant

$\square$ Combination

Name of consultant*:

Comment:

10. Is it the same person(s) that inspects the same bridges or does it vary?

$\square \quad$ Same

$\square$ Different

Combination/depends

$\square$ Don't know

Comment:

11. Choose a) and/or b)

a) How many times a year is a bridge generally inspected?

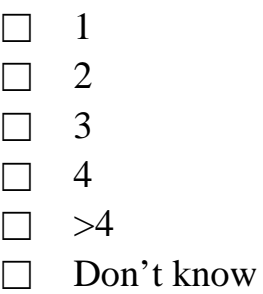

Comment:

b) If the bridges are inspected less than 1 time per year, how large gaps are there between inspections?
2 years
3 years
4 years
5 years

$\square \quad>5$ years

Don't know 
Nordic Concrete Research - Publ. No. NCR 58 - ISSUE 1 / 2018 - Article 8, pp. 127-142

Comment:

12. When are the bridges inspected?

$\begin{array}{ll}\square & \text { January } \\ \square & \text { February } \\ \square & \text { March } \\ \square & \text { April } \\ \square & \text { May } \\ \square & \text { June } \\ \square & \text { July } \\ \square & \text { August } \\ \square & \text { September } \\ \square & \text { October } \\ \square & \text { November } \\ \square & \text { December } \\ \square & \text { Don't know }\end{array}$

Comment:

Maintenance

13. How large part of the bridges is salted with de-icing salts each year?

(This means on the roads both on and under the bridge)

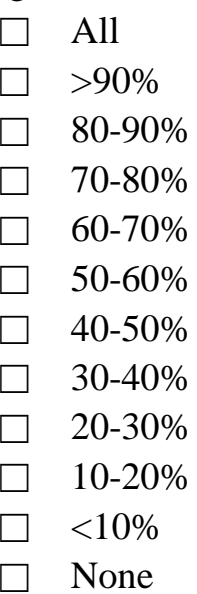

Comment:

14. During which months are de-icing salts used?

(This means on the roads both on and under the bridge)

$$
\begin{array}{ll}
\square & \text { January } \\
\square & \text { February } \\
\square & \text { March }
\end{array}
$$

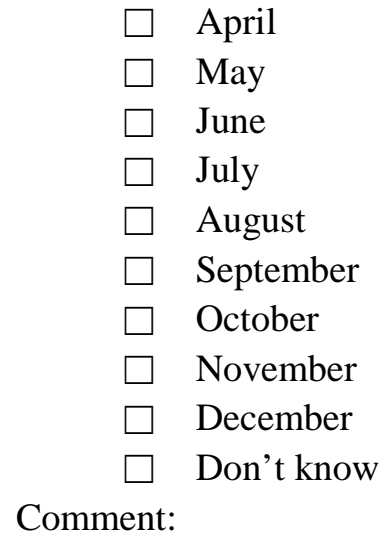

15. When are the bridges washed?
$\square$ January
February
March
April
May
June
July
August
$\square$ September
$\square$ October
$\square$ November
December
Don't know

Comment:

Demands

16. Do you base your demands on the STA's documents on demands and advice?

$$
\begin{aligned}
& \text { Yes, current } \\
& \text { Yes, previous version } \\
& \text { Even older } \\
& \text { No, other document(s) }
\end{aligned}
$$

If other, the document's name:

Comment:

17. Which instruction or demands do you have on washing?

(If a reference is used, please name it) Answer: 
18. What is the most common problem? (not counting accidents)

Answer:

19. What is the most common measure? (in regards to the previous question)

Answer:

20. Are the measures considered to have had a positive effect on the bridge standard? Answer:

21. Are the demands you have fulfilled?

$$
\begin{array}{ll}
\square \quad \text { Yes } \\
\square \quad \text { No }
\end{array}
$$

Comment:

22. Out of the demands you have on bridge maintenance, is it something you wish would be further investigated?

Answer:

23. If the following documents are used, TDOK Krav (2013:0415) and Råd (2013:0416), are additional demands included in the contracts?

$$
\begin{array}{ll}
\square & \text { Yes } \\
\square \quad \text { No } \\
\square \quad \text { Sometime }
\end{array}
$$

Comment:

\section{Control/Checks}

24. Who performs the check/control? Answer:

25. How do you verify that the maintenance and demands have been fulfilled?

Answer:
26. Do you have any controls or investigations that you which to be furthered investigated?

Answer:

27. What happens if the control shows shortcomings in the preventive bridge maintenance?

Answer:

28. Do you use BaTMan?
$\square$ Yes
$\square$ No
$\square$ Have own system

Comment:

29. What is the outcome of the latest checks/controls?

Answer:

Other

30. How would you define preventive maintenance? What does it include?

Answer:

31. Would it be possible to get in contact with you again concerning additional questions/developments?

$$
\begin{aligned}
& \text { Yes } \\
& \text { No } \\
& \text { Maybe }
\end{aligned}
$$

Comment: 